\title{
Assessing building energy efficiency with the help of specific heat demand characteristics: boreal regions of Russia case study
}

\author{
Lyazzat Junussova ${ }^{1}$, Andrey Zhuikov ${ }^{2}$, Anatoly Matiushenko ${ }^{2}$, Stanislav Chicherin ${ }^{3, *}$, and \\ Anna Ilicheva $^{4}$ \\ ${ }^{1}$ Non-profit JSC Almaty University of Power Engineering and Telecommunications, Almaty, \\ Kazakhstan \\ ${ }^{2}$ Siberian Federal University, Svobodny Ave., 79, 660041 Krasnoyarsk, Russia \\ ${ }^{3}$ Omsk State Transport University (OSTU), Marx avenue, 35, 644046 Omsk, Russia \\ ${ }^{4}$ Omsk State Technical University, Mira, h. 11, 644050 Omsk, Russian Federation
}

\begin{abstract}
When data on certain variables is not available for the construction of a building, generalized models are used to assess their heat consumption. However, buildings and their associated substations in the district heating $(\mathrm{DH})$ network of a city have pretty different parameters. Therefore, an error up to $30 \%$ is achieved and moreover that type of assessing results into illogical conclusions. To deal with it, the feasibility and validity of the heat demand characteristics should be verified by a handheld thermal camera at the ground level. The primary way is to improve overall DH system efficiency by reducing distribution losses and ensuring correct supply and return temperatures, other ways are related to reduction of heat losses at a demand side.
\end{abstract}

\section{Introduction}

Low temperature district heating (LTDH) so popular in EU now [1] stands for district heating $(\mathrm{DH})$ with considerably lowered supply and return temperatures compared to conventional district heating featuring decreasing losses and low operation costs [2]. The financial feasibility of LTDH is challenged as the heat consumption density is reduced, which generally decreases the profitability of DH systems [3]. When data on certain variables is not available for the construction of a building, generalized models are used to assess their distribution or the value of their characteristics. Seldom their values are obtained based on expert opinion, but more often with the help of national construction code [4]. However, buildings and their associated substations in the DH network of a city have pretty different parameters [5]. Another concern for vast spreading of LTDH in Russia is low indicators of DH system reliability and no availability year round [6].

\footnotetext{
*Corresponding author: man_csv@hotmail.com
} 


\section{Materials and methods}

Demand side measures involves enhancing the thermal resistance of building envelopes and can be measured as follows.

$$
\mathrm{q}_{h}=\frac{\mathrm{P}}{\mathrm{S}} \cdot \mathrm{K}_{w}+\frac{1}{\mathrm{~L}} \cdot \mathrm{K}_{f},
$$

Where qh specific building heat demand $[\mathrm{J} / \mathrm{sm} 3 \mathrm{~K}]$,

$\mathrm{Kw}$ mean heat transfer factor of outer walls $[\mathrm{W} / \mathrm{m} 2 \mathrm{~K}]$,

$\mathrm{Kf}$ mean heat transfer factor of outer floor and ceiling [W/m2K],

$P$ building perimeter $[\mathrm{m}]$,

$\mathrm{S}$ building surface area $[\mathrm{m} 2]$,

L elevation [m].

If the detailed data of each building in the reference-group is available and the target is assumed to follow a normal distribution, specific building heat demand can be described according to professor Ermolaev distance via its relation to infiltration rate, etc.:

$$
\mathrm{q}_{h}=\left[\frac{\mathrm{P}}{\mathrm{S}}\left(\left(\mathrm{K}_{w}+\varphi \cdot\left(\mathrm{K}_{w i}-\mathrm{K}_{w}\right)\right)+\frac{1}{\mathrm{~L}} \cdot \mathrm{K}_{f}\right] \cdot(1+\mu),\right.
$$

$\varphi$ glazing ratio,

$\mu$ infiltration rate,

Kwi window heat transfer factor $[\mathrm{W} / \mathrm{m} 2 \mathrm{~K}]$.

\section{Results and discussion}

Fig. 1 shows the results of the plotting the specific heat demand for typical DOTs in EU (up to $-10^{\circ} \mathrm{C}$ ) and European part of Russia (up to $-30^{\circ} \mathrm{C}$, refer to $-25^{\circ} \mathrm{C}$ in Moscow).

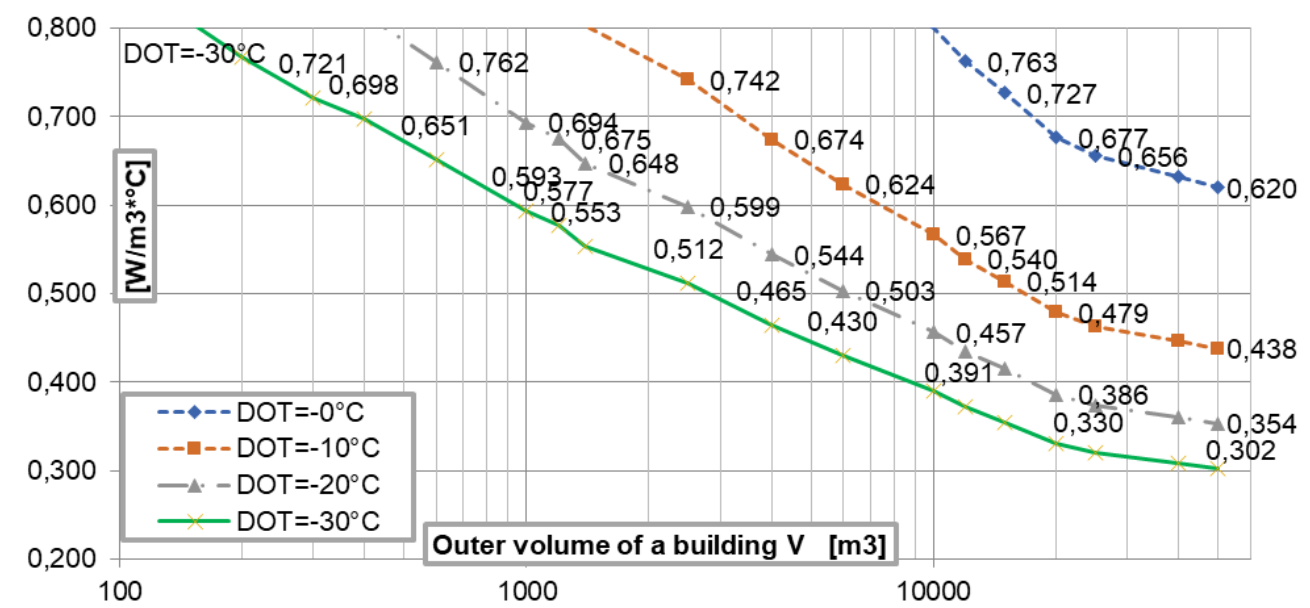

Fig. 1. Consumption of energy for space heating of residential buildings [per $\mathrm{m} 3$ of an outer volume] for DOT ranging between 0 and $-30^{\circ} \mathrm{C}$

In Fig. 2, that is plotted for the building volume up to $50,000 \mathrm{~m} 3$ as well and the ordinary in boreal regions outdoor temperatures up to $-50^{\circ} \mathrm{C}$, and y-axis still represents the same range. 


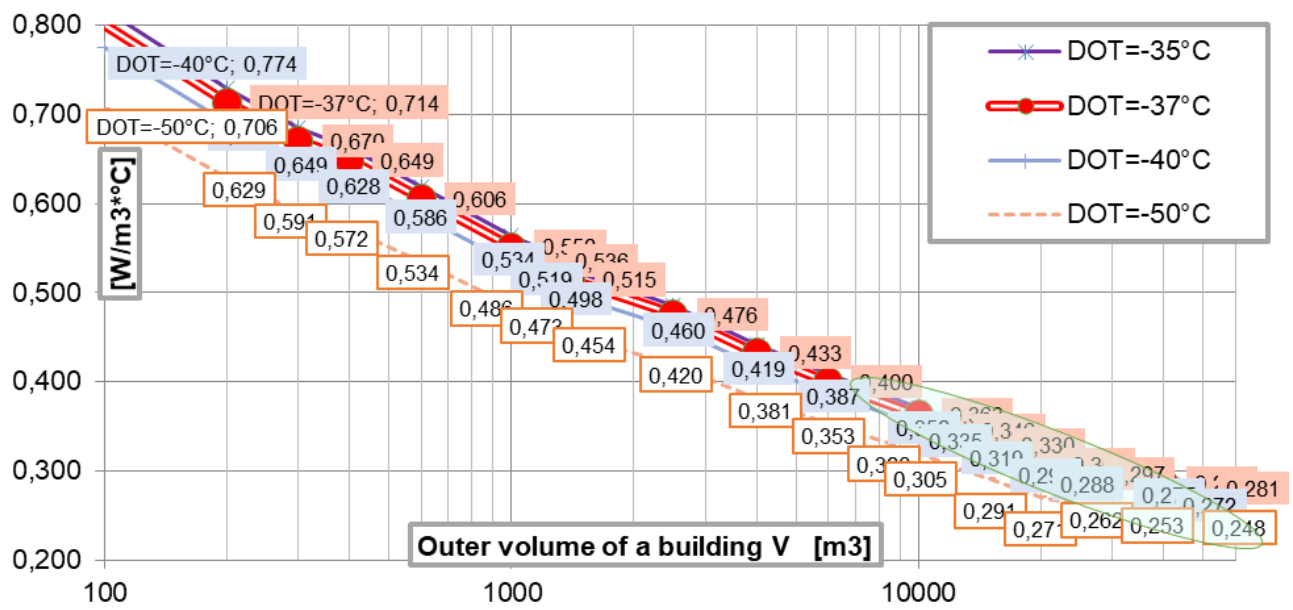

Fig. 2. Consumption of energy for space heating of residential buildings [per $\mathrm{m} 3$ of an outer volume] for DOT ranging between -35 and $-50^{\circ} \mathrm{C}$

Although it works quite well in moderately cold (boreal) regions - refer to fig. 1 - that leads to incorrect results in others. The error up to $30 \%$ is achieved and moreover that type of assessing results into illogical conclusions. For instance, considering this approach there is no reasonable difference of assessing heat consumption of a large building (more than $5,000 \mathrm{~m} 3$ ) located in a region with a DOT -35 and $-50^{\circ} \mathrm{C}$, refer to the green-outlined area in fig. 2.

As heating generally happens in the winter, the temperature difference exists between the indoor space and the outside surroundings. If a defect exists, the temperature of the wall surrounding the faulty point increases and manifests in a thermal image. As a result, this method is able to assess the real state of envelopes and provide recommendations. Therefore, the feasibility and validity of the heat demand characteristics should be verified by a handheld thermal camera at the ground level as that already widely distributed for locating leaks and large-scale monitoring of DH systems using remote sensing from an aircraft with a thermal camera [7]. Even a fault in the flow control valve at a substation is a reason for overconsuming the energy [5].

\section{Conclusion}

The primary way is to improve overall DH system efficiency by reducing distribution losses and ensuring correct supply and return temperatures depending on weather conditions and certain system structure. For instance, when a two-pipe connection (primary energy source is the high-temperature supply pipe, where the return flow is mixed into) is correctly maintained, the pumping costs are lower [8]. During the reconstruction of a DH system into the 4th generation one, both supply and return temperatures are possible to decrease [9].

Other ways to enhance building energy performance are related to reduction of heat losses by means of:

(1) constant measurement, diagnosis, and load control at a substation. However, according to [10] most substations in Russia are still not properly equipped for connecting to a SCADA system with thermostatic or electronic control for space heating or domestic hot water preparation.

(2) increase of thermal resistance of barrier constructions, additional thermal insulation.

(3) decreasing the glazing surface. 
(4) glazing outer balconies, loggias, terraces, patios and so forth, if not yet.

(5) replacing worn windows with double and triple glazing ones.

\section{Acknowledgment}

The reported study was funded by the Administration of Krasnoyarsk Krai and the Krasnoyarsk Krai Foundation for Support of Scientific and Technical Activity.

\section{References}

1. Von Rhein, J., Henze, G. P., Long, N. \& Fu, Y, Energy Conversion and Management, 196, 705 (2019)

2. Arabkoohsar, A. \& Alsagri, A. S., Energy, 193, 116781 (2020)

3. Meesenburg, W., Ommen, T., Thorsen, J. E. \& Elmegaard, B., Energy, 191, 116496 (2020)

4. Chicherin, S.; Mašatin, V.; Siirde, A.; Volkova, A., Energies, 13, 4505 (2020)

5. Farouq S., Byttner S., Bouguelia M.-R., Nord N. \& Gadd H., Engineering Applications of Artificial Intelligence, 90, 103492 (2020)

6. Chicherin, S., Energy, 211, 118603 (2020)

7. Zhou, S., O’Neill, Z. \& O’Neill, C. Applied Thermal Engineering, 137, 567 (2018)

8. Volkova, A., Energy, 198, 117304 (2020)

9. Lipovka Y.L., \& Belilovets V.I., Journal of Siberian Federal University, 9(4), 546 (2016)

10. Volkova A., Mašatin V., \& Siirde A., Energy, 150, 253 (2018) 